REVISTA DE LA CEPAL 83 *AgOSTO 2004

\section{Crecimiento, competitividad y empleo en Perú, 1990-2003}

\author{
Norberto E. García
}

$\mathrm{E}$

crecimiento del empleo de calidad necesario para disminuir el empleo informal y el desempleo en Perú, depende de que se acelere y diversifique la inversión privada en el sector transable. Una de las principales restricciones para acelerarla es la débil competitividad del sector transable no extractivo. En 1990-2003, la mejora de su competitividad se basó esencialmente en el descenso de los costos laborales, enfoque socialmente injusto y económicamente ineficaz. Para elevar la competitividad es indispensable un régimen macroeconómico con un tipo de cambio real competitivo y estable — cuya aplicación enfrenta obstáculos - y el aumento de la productividad total a nivel microeconómico. Esto último debe buscarse a través de políticas microeconómicas y mesoeconómicas, siendo el principal obstáculo la visión estrecha que dominó el escenario económico en el decenio de 1990, según la cual el incremento de la competitividad se logra redu-

Norberto E. García Investigador Asociado del Instituto de Estudios Peruanos (IEP) e Investigador Líder de la Red de Políticas de Empleo del Consorcio de Investigaciones Económicas y Sociales (CIES) Perú

• ngarcia@terra.com.pe ciendo los costos laborales medios. 


\section{Empleo, pobreza y crecimiento}

En Perú existe un estrecho vínculo entre el tipo de empleos generados y la evolución de la pobreza. Para las familias de ingresos medios y bajos, la principal fuente de ingresos es el trabajo de sus miembros ocupados. No debería sorprendernos entonces que la pobreza se mantenga a niveles muy altos, puesto que la mayoría de los empleos generados en el decenio de 1990 era de muy baja calidad, en términos de productividad, ingresos, estabilidad y protección social asociada. En dicho decenio el empleo formal creció a una tasa anual de $1,2 \%$, mientras que el empleo informal lo hizo a un ritmo de 4,7\% al año, acentuándose así la tendencia observada en décadas anteriores.

En la actualidad, menos de $25 \%$ de los peruanos activos tiene acceso a un empleo estable cuya productividad permita una remuneración digna. El 75\% restante se desempeña en actividades independientes informales de muy baja productividad, en labores agrícolas con una productividad aun menor, como asalariados sin contrato laboral en microempresas informales que no brindan estabilidad ni un ingreso digno, o se encuentra abiertamente desempleado en las zonas urbanas del país. Es importante señalar que sólo un $10 \%$ de este $75 \%$ está en situación de desempleo abierto, mientras que la mayor parte del $90 \%$ restante se inserta en ocupaciones de muy baja productividad. Por consiguiente, el problema del empleo en Perú es percibido por su población no tanto como desempleo abierto, sino principalmente como una muy baja expectativa de tener un empleo digno y estable que contribuya a elevar su nivel de vida.

Por el lado de los ingresos laborales, entre 1980 y 1991 los salarios registraron una caída de 65\%. Pese a la recuperación observada en 1992-1997, en el año 2000 estaban todavía muy por debajo del nivel de 1980, y los ingresos de la mayor parte de los trabajadores informales y agrícolas eran inferiores a la línea de pobreza por persona activa. La participación de las remuneraciones en el producto interno bruto (PIB) se redujo de $37 \%$ en 1978 a $32 \%$ en 1992 y $24,5 \%$ en $2001 .^{1}$

Las magnitudes expuestas indican que el problema del empleo en Perú no puede abordarse sólo con políticas de corto plazo, políticas activas de empleo y programas de empleo directo, que por su naturaleza inciden en no más de un 5 ó $6 \%$ de la población económicamente activa (PEA). Debe enfrentarse entonces con una política de mediano y largo plazo, es decir, con una estrategia de crecimiento.

A mediano plazo, el incremento del empleo de calidad está determinado por el ritmo de crecimiento de la inversión. Tanto el aumento del empleo de calidad en los segmentos modernos como los recursos necesarios para transformar productivamente los segmentos atrasados y mejorar la situación de los allí ocupados, dependen de que se acelere la inversión y el crecimiento económico.

\section{II}

\section{La política macroeconómica reciente}

La administración que asumió a mediados de 2001 heredó una recesión que se inició en 1998 y se profundizó hasta principios de 2002. Desde mediados de 2001 se llevó adelante una política de reactivación que incluyó un aumento mesurado del gasto público y una política monetaria expansiva y focalizada en el descenso de la tasa de interés interna. Esta política logró sacar al país de la recesión sin elevar la tasa inflacionaria, pero se ocupó poco de la mejora de la competitividad. Así, impulsado por la reactivación y la puesta en mar- cha de nuevos proyectos extractivos, el crecimiento del PIB fue de 4,9\% en 2002 y de 4,0\% en 2003 (INEI, 2004).

Junto con aumentar el gasto público, en 20012003 se redujo el déficit fiscal, debido al aumento de

\footnotetext{
1 Tres choques explican esta tendencia: la crisis de la deuda de principios del decenio de 1980, la hiperinflación de 1989-1990 y la desregulación laboral que siguió de hecho a la reforma laboral "flexibilizadora" de la década de 1990.
} 
los ingresos tributarios y, sobre todo, del endeudamiento externo público en 2002-2003; esto acentuó la vulnerabilidad financiera y real frente a un eventual repunte de la tasa de interés internacional.

Se suponía que la reactivación vía gasto público y baja de la tasa de interés, unida a una política de equilibrios macroeconómicos y de estabilidad de los precios y del tipo de cambio real (a través de una flotación sucia), abrirían el camino al aumento de la inversión privada. No obstante, la inversión bruta total, que había caído $26 \%$ en 1997-2001, creció sólo 0,7\% en 2002 y 4,0\% en 2003, año en que el coeficiente de inversión bruta total se situó en 15,2\% del PIB. Esta cifra estaba aproximadamente 10 puntos porcentuales por debajo de la necesaria para alcanzar el crecimiento económico anual de $7 \%$ que se requeriría para ir reduciendo el problema de empleo. En particular, las importaciones mensuales de bienes de capital siguieron siendo bajas en 2001-2003, pese a la incidencia de los grandes proyectos de Antamina y Camisea, ${ }^{2}$ y lo mismo señalan los registros mensuales de las inversiones en construcción. La debilidad de la inversión privada se explica en parte por la desaceleración de las principales economías del Norte en 1999-2002. Pero también, como se verá posteriormente, existen razones internas más profundas.

El impulso derivado del aumento del gasto público y de la expansión monetaria en 2001 y 2002 tendió a diluirse con el transcurso del tiempo. Desde fines de 2003 se percibe una nueva desaceleración del PIB y del empleo, a pesar de la liquidez existente. El repentino aumento de las exportaciones a principios de 2003 (la tasa del año llegó a 15\%) compensó en parte el debilitamiento del efecto expansivo del gasto público y de la política monetaria. Como el $70 \%$ de ese aumento se debió a alzas en los precios y el volumen de los productos básicos tradicionales exportados por Perú, es difícil otorgarle carácter permanente. Aunque también es cierto que crecen rápidamente las exportaciones no tradicionales.

El crecimiento por reactivación en 2001-2002 generó un crecimiento muy bajo del empleo formal y un incremento alto del empleo informal, en línea con el muy escaso crecimiento de la inversión privada y pública y reproduciendo las tendencias de largo plazo. La ausencia de un fuerte impulso inversor contribuyó a un muy escaso aumento del empleo de calidad.

En las circunstancias descritas, cobra vida el debate en torno al rumbo que ha de seguirse y las políticas que han de adoptarse para acelerar la inversión privada y lograr un crecimiento sostenido del empleo de calidad. Este trabajo plantea una hipótesis como aporte a ese debate, centrando la atención en los sectores modernos formales de la economía peruana, ya que es allí donde se ubica el obstáculo principal para lograr un crecimiento alto y sustentable. Un crecimiento elevado en los segmentos modernos es condición necesaria, pero no suficiente, para lograr la transformación productiva de los segmentos atrasados y su incorporación al crecimiento: así lo sugieren, entre otras experiencias, las de Chile (1983-2003) y México (1986-2003).

\section{III}

\section{Un curso estratégico}

La economía peruana enfrenta dos grandes problemas prioritarios: su débil competitividad y la necesidad de crear empleos de calidad. Por consiguiente, cualquier estrategia de crecimiento debe necesariamente atacar ambos frentes.

En una economía pequeña, abierta y endeudada como la peruana, lo anterior implica aplicar políticas a nivel macroeconómico, mesoeconómico y microeconómico para: i) acelerar decisiones de inversión privada

\footnotetext{
${ }^{2}$ Compañía Minera Antamina y Yacimiento de Gas Camisea.
}

en sectores transables (productores de bienes y servicios exportables e importables), y ii) ampliar los mercados para esos bienes y servicios. La combinación de políticas de los tres niveles indicados es lo relevante en una concepción estratégica (García, 2004).

Como ha sucedido en otros países de América Latina, Perú se integró mucho más plenamente a los mercados financieros internacionales - a través del endeudamiento y la entrada de capitales - que a los mercados comerciales externos, donde sigue siendo esencialmente un exportador de productos primarios sujetos a fluctuaciones. Este desequilibrio en su inserción 
externa debe ser corregido para que el país pueda acelerar el crecimiento de las exportaciones, crecer a un ritmo alto, reducir el peso del pago de la deuda y generar empleo. Si se desea acelerar las exportaciones, hay que saber cuáles son las de comportamiento más dinámico en el ámbito mundial, esto es, considerar la calidad de su inserción comercial y no sólo el coeficiente de apertura (Svarzman, 2004).

En 1990-2000 las exportaciones mundiales de productos primarios - lo que exporta Perú- han sido las de más lento crecimiento. Esto si se las compara con las de alta tecnología, que hacen uso intensivo de conocimiento y capacidades; con las de tecnología intermedia, cuyos productos y procesos se basan en economías de escala y que crecieron por encima del promedio; o incluso con las de baja tecnología, como confecciones y calzado, o las de manufacturas que hacen uso intensivo de recursos naturales (Svarzman, 2004). Sólo la gran demanda de productos primarios extractivos originada en el alto crecimiento de China alteró a partir de 2003 esa tendencia, al presionar sobre la oferta de commodities. Sin embargo, es difícil suponer que este hecho ha de modificar en forma permanente las tendencias estructurales en materia de exportaciones de productos primarios.

Por consiguiente, la política económica debería crear las condiciones para consolidar lo avanzado en materia de exportaciones y estimular gradualmente la producción de bienes y servicios de mayor demanda en mercados internacionales y con mayor valor agregado. En particular, para Perú son importantes las exportaciones de bienes y servicios que hacen uso intensivo de recursos naturales, pero que han sido sometidos a procesamientos posteriores para elevar su valor agregado mediante un mayor contenido de empleo y mejores eslabonamientos de empleo hacia atrás.

El factor prioritario es el rápido aumento de la inversión privada en productos transables (particularmente exportables). El constante aumento de la disponibilidad de divisas así logrado es una condición necesaria pero no suficiente, en una economía endeudada externamente como la peruana, para lograr un crecimiento más rápido de la inversión en productos no transables y, por ende, de la inversión en los segmentos modernos en su conjunto. Cabe señalar que la dinamización de los sectores no transables no es automática - como lo señala la experiencia de México en 1994-2002- y que se necesitan acciones y políticas para lograrla.

A su vez, un crecimiento alto y sostenido de la inversión privada en productos transables, que sea acompañado también por un aumento de la inversión privada en productos no transables de segmentos modernos, permite la generación sostenida de empleos de calidad a un ritmo elevado en los segmentos modernos y proporciona los recursos necesarios para la transformación productiva de los segmentos atrasados, si se consigue profundizar las políticas de transformación productiva e ir articulando los segmentos rezagados con el crecimiento de los segmentos modernos.

Las estimaciones preliminares efectuadas para este trabajo muestran que para lograr un crecimiento del empleo de calidad de $4 \%$ anual en los próximos años - cifra indispensable para absorber el alto crecimiento de la PEA en los segmentos modernos y reducir significativamente la informalidad en un plazo razonable- la inversión privada en sectores transables deberá aumentar aproximadamente en $8 \%$ anual, lo que demandará un aumento anual de las exportaciones de casi $9 \%$. Estas cifras son compatibles con un crecimiento sostenido del PIB de $7 \%$ anual. $^{3}$

Con un crecimiento anual sostenido de la inversión privada en sectores transables que supere ligeramente el $8 \%$ y que induzca un incremento anual de la inversión en no transables de $7 \%$, en veinte años el empleo de calidad casi se triplicaría, gracias a los nuevos empleos de mayor productividad y al aumento de las remuneraciones reales inducido por la mejora de la productividad. Dado el alto ritmo de crecimiento esperado de la PEA total, superior al 2,6\% anual, el bolsón de ocupados en niveles de muy baja productividad se reduciría desde un $67 \%$ a cerca de $39 \%$. Sobre dicho bolsón deberían incidir, paralelamente, las políticas orientadas a transformar y mejorar la productividad de los allí ubicados.

Aun cuando se haga hincapié, correctamente, en que los factores decisivos para acelerar la inversión privada son: i) los equilibrios macroeconómicos, ii) la estabilidad de las reglas del juego para la inversión pri-

\footnotetext{
${ }^{3}$ Las proyecciones expuestas en el texto fueron elaboradas con la expresión reducida del modelo que se presenta en forma completa en García (2002a). Se trata de un modelo de macroempleo que distingue entre un sector transable y otro no transable, e incorpora funciones que ajustan la rentabilidad de la inversión privada a través del tipo de cambio real y la productividad total. La inversión en sectores transables y no transables depende de la rentabilidad y aumentos esperados de la demanda de productos transables. El incremento de la inversión en cada sector determina el crecimiento a mediano plazo del empleo, dado el aumento ya citado de la productividad total de cada sector. El modelo distingue un sector de empleo de calidad vinculado al comportamiento de los sectores transables y no transables, y un sector de empleo de baja calidad, vinculado a segmentos atrasados rurales y urbanos.
} 
vada, iii) la seguridad jurídica y iv) la credibilidad del gobierno y el país y la confianza en ellos, hay que tener en cuenta un quinto factor omitido: la competitividad, que determina la rentabilidad de la inversión privada, necesaria para que las empresas inviertan al alto ritmo requerido.

Una rentabilidad elevada de los sectores transables no extractivos es indispensable para atraer nuevos emprendimientos y diversificar la inversión en ellos, actualmente concentrada en minería, pesca industrial y gas e hidrocarburos. Una alta rentabilidad es también necesaria para transferir parte de ella a menores precios y mayor calidad. En un enfoque de largo plazo, la rentabilidad de los sectores transables no extractivos debe alcanzar gradualmente el nivel que se necesita para inducir un alto crecimiento de la inversión privada en ellos.

En el caso de Perú, la rentabilidad depende esencialmente del aumento de la competitividad de las empresas y del país. La competitividad está determinada por el tipo de cambio real y la productividad total a nivel microeconómico — de todos los recursos utilizados por las empresas-, incluyendo la infraestructura productiva y otros factores del entorno microeconómico. Para elevar la rentabilidad en sectores transables no extractivos a los niveles requeridos, es indispensable: i) contar con un tipo de cambio real competitivo y estable que, en una fase de ignición, estimule decisiones de invertir; ii) comenzar a reducir la diferencia entre la productividad total de Perú y la de los países competidores. Elevar la productividad total a nivel microeconómico reduce los costos totales unitarios, da margen a mejoras de calidad y permite aumentar la rentabilidad de la inversión. Pero como este proceso tiene un plazo de maduración significativo, es importante contar con un tipo de cambio real competitivo y estable, que puede ser implementado con mayor rapidez y sostenido hasta que se logre el crecimiento sustentable de dicha productividad total.

Cabe señalar también que una rentabilidad elevada es condición necesaria pero no suficiente. Si se trata de impulsar expectativas e imprimir dinamismo a las decisiones de inversión privadas en un escenario como el actual, habrá que efectuar fuertes cambios institucionales que estimulen esas decisiones. Los nuevos convenios de comercio exterior pueden cumplir esa función.

En la práctica, se trata de estimular decisiones de inversión privada locales, ya que un porcentaje muy alto de la inversión esperada es interna y no externa.

\section{IV}

\section{Crecimiento de la inversión privada, tipo de cambio real y productividad}

En un contexto como el del Perú, la rentabilidad en sectores transables no extractivos está determinada, esencialmente, por la evolución del tipo de cambio real y por el ritmo de aumento de la productividad total a nivel microeconómico. Veamos cómo se comportaron estas variables en el pasado reciente.

\section{Tipo de cambio real}

Como muestra el gráfico 1, en Perú el tipo de cambio real (TCR) multilateral ha caído persistentemente. Desde principios de 1985 hasta comienzos de 2003 bajó cerca de 64\%, según las series estadísticas del Banco Central de Reserva de Perú (BCRP), y $73 \%$ entre 1985 y 1992, tomando en este caso como año de comparación uno posterior al programa de shock de 1990. Si se retrocede hasta fines del decenio de 1970, se obser- va también un apreciable descenso, de 70\%, entre 1978 y 1995 (Moguillansky, 1996). Aunque la hiperinflación de 1989-1990 hubiese distorsionado los datos, y el descenso efectivo del tipo de cambio real fuese menor que el registrado en las series estadísticas, es indudable que el tipo de cambio real multilateral cayó significativamente entre 1978 y 1992, porque aun antes de 1990 ya se había observado un fuerte descenso (en 1978-1989). De 1992 a 1994 tuvo una leve recuperación y de ahí en adelante, con fluctuaciones, tendió a permanecer estable hasta 2002. En 2003, el BCRP tuvo éxito en acompañar la depreciación del dólar, lo que desembocó en una recuperación parcial del tipo de cambio real multilateral.

La relación de precios entre los productos transables y no transables, medida por el índice del BCRP, cayó 68\% en 1985-2002, confirmando así que el 
GRAFICO 1

Perú: Evolución del tipo de cambio real, 1985-2003

(Índices del tipo de cambio real, 1994=100)

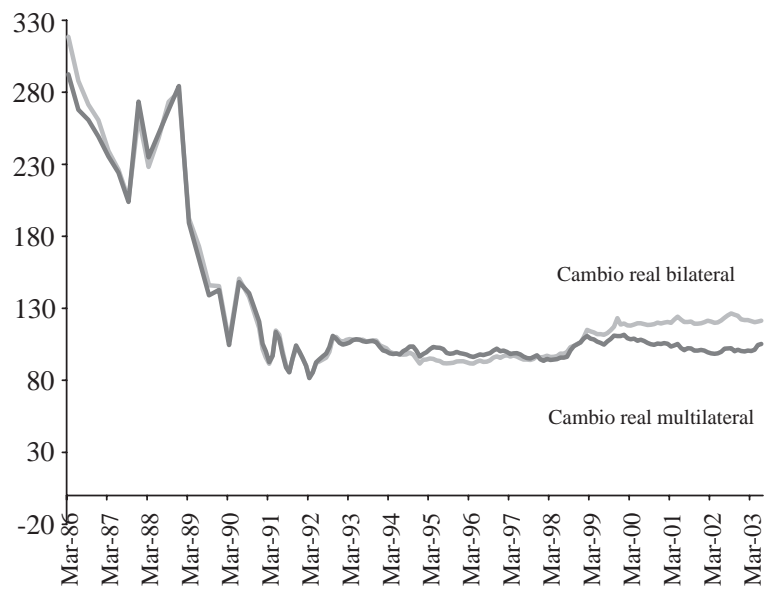

Fuente: Series estadísticas, boletines mensuales y base de datos del Banco Central de Reserva de Perú (BCRP).

descenso del tipo de cambio real redujo notablemente la rentabilidad media de los transables, aun cuando también aquí la hiperinflación de 1989-1990 puede estar llevando a sobreestimar la magnitud del descenso. De esta tendencia deriva el empeoramiento de los precios relativos para el sector agrícola y el sector turismo, con efectos adversos sobre la rentabilidad de ambos. En la economía peruana, tanto la agricultura como el turismo son importantes proveedores de divisas y generadores de empleo directo e indirecto.

Conviene hacer presente que la objeción al alza del tipo de cambio real por su impacto adverso sobre los salarios reales deja de tener peso cuando esa alza es gradual y el ritmo de aumento de la productividad compensa su efecto sobre los salarios.

\section{La productividad total}

El segundo factor relevante para la rentabilidad es el comportamiento de la productividad total a nivel microeconómico. Es importante aquí la productividad de todos los recursos utilizados por las empresas y, además, la oferta de infraestructura crítica para la competitividad. Los indicadores disponibles son macroeconómicos, que agregan los comportamientos microeconómicos.

Como se desprende del cuadro 1, todos los estudios empíricos disponibles muestran un considerable estancamiento o incluso descenso de la productividad total en 1970-1990, seguido por una leve alza en 1990-
1997 que osciló — - según el autor de que se trate- en torno al $1 \%$ anual. A partir de este último año, es muy probable que la recesión que afectó al país en 19982001 haya contribuido al descenso de la productividad total. Un trabajo reciente del Banco Mundial (De Ferranti y otros, 2003) confirma los resultados expuestos para los decenios de 1970 y 1980 y estima un crecimiento de la productividad total de $0,7 \%$ anual en 1991-1997. Por lo tanto, en 1970-2000 la productividad total de Perú exhibió un virtual estancamiento como tendencia neta de largo plazo, en circunstancias de que muchos de los países con que compite (China, Chile, Estados Unidos, Japón, la República de Corea y otros) exhiben alta productividad y/o registran en ella avances significativos, de 1 a $4 \%$ anual. En un estudio reciente (García, 2002a) se afirma que el estancamiento a mediano plazo de la productividad aparente por sectores fue un fenómeno difundido en todas las ramas de actividad, salvo la minería.

Un indicador que ratifica las tendencias en materia de productividad total es el comportamiento a largo plazo de la inversión en maquinaria y equipo como proporción del PIB. Según señala Iguiñiz (2001), este indicador bajó de $24 \%$ en 1975 a aproximadamente $8,6 \%$ en 2001. La acumulación de capital a largo plazo en maquinaria y equipo es en sí un indicador significativo, dado su efecto sobre la composición del acervo de capital y, por ende, sobre la productividad total. Pero además es importante porque complementa otras variables clave que forman parte del acervo de capital. Este acervo, definido en un sentido amplio, abarca el crecimiento a largo plazo de la proporción de mano de obra capacitada, la difusión de criterios de gestión en materia de productividad y competitividad, el aumento del conjunto de conocimientos específicos para lograr mejoras de productividad, la introducción de innovaciones tecnológicas blandas y duras, y otros aspectos. Dicho de otro modo, la caída en la proporción del PIB destinada a inversión en maquinaria y equipo está advirtiendo que hay otros factores clave para elevar la productividad — como los enumerados - que están siendo también afectados u omitidos. Esto lo confirma el propio Iguiñiz (2001) cuando verifica que el gasto público real en educación por alumno, utilizado como variable sustitutiva de la calidad del gasto en educación para el $80 \%$ de menores ingresos, declinó persistentemente desde fines del decenio de $1960 \mathrm{y}$ actualmente es inferior en $50 \%$ al de 1968 .

Además, los análisis empíricos de Porter (2003) confirman lo expuesto, al señalar que Perú se encuen- 
CUADRO 1

Perú: Estimaciones de la productividad total de los factores, 1950-1959 a 1991-2000

(Variaciones anuales medias, en porcentajes)

\begin{tabular}{|c|c|c|c|c|c|c|}
\hline Período & IPE & $\begin{array}{c}\text { Beltrán y } \\
\text { Seminario } \\
\text { (1998) }\end{array}$ & $\begin{array}{c}\text { Vega } \\
\text { Centeno } \\
(1989)\end{array}$ & $\begin{array}{c}\text { Vega } \\
\text { Centeno } \\
(1997)\end{array}$ & $\begin{array}{c}\text { Vallejos y } \\
\text { Valdivia } \\
\text { (1999) }\end{array}$ & $\begin{array}{c}\text { Calvo y } \\
\text { Bonilla } \\
(1998)\end{array}$ \\
\hline $1950-59$ & $1,5^{\mathrm{a}}$ & 1,0 & 1,5 & 1,1 & 2,7 & $\ldots$ \\
\hline $1960-69$ & $1,4^{\mathrm{b}}$ & 2,5 & 2,0 & 1,3 & 1,7 & $\ldots$ \\
\hline $1970-80$ & $-0,8^{\mathrm{c}}$ & 0,3 & 1,1 & $-0,8$ & $-0,6$ & $\ldots$ \\
\hline $1981-90$ & $-3,9$ & $-3,6$ & $0,3^{\mathrm{d}}$ & $-2,4$ & $-4,0^{\mathrm{e}}$ & $\ldots$ \\
\hline $1991-2000$ & 1,0 & $3,4^{\mathrm{f}}$ & $\ldots$ & $-0,4^{\mathrm{g}}$ & $1,8^{\mathrm{h}}$ & $1,8^{\mathrm{i}}$ \\
\hline
\end{tabular}

Fuente: Instituto Peruano de Economía (IPE, 2001).

a 1951-1960. b 1961-1970. c 1971-1980. d1981-1988. e 1980-1990. ${ }^{\mathrm{f}} 1991-1995 .{ }^{\mathrm{g}} 1991-1996 .{ }^{\mathrm{h}} 1991-1998 .{ }^{\mathrm{i}} 1993-1996$

tra entre los países más atrasados en materia de competitividad microeconómica, como se verá posteriormente.

En síntesis, las tendencias del tipo de cambio real y de la productividad total impulsaron la baja a largo plazo de la rentabilidad en los sectores transables no extractivos.

Por consiguiente, la reducción de aranceles y la eliminación de controles administrativos que se llevaron a cabo en los primeros años del decenio de 1990 se hicieron con un tipo de cambio real en descenso y una productividad total muy baja. Todo esto afectó sin duda la protección efectiva y la rentabilidad de los sectores transables, ante lo cual la válvula de escape fue la reducción de los costos laborales medios. Como se verá en una sección posterior, la reducción de tales costos sólo compensó parcialmente el efecto combina- do de la caída del tipo de cambio real, la apertura comercial y una productividad estancada. Aunque permitió la sobrevivencia y el nacimiento de algunas actividades transables cuya productividad les aseguraba un margen competitivo, no fue suficiente para impulsar significativamente la diversificación de las inversiones en productos exportables ni la sustitución competitiva de importaciones, lo que tuvo repercusiones graves para el empleo.

Dicho de otro modo, como consecuencia de las tendencias descritas, la tasa de protección efectiva sobre las utilidades se redujo sensiblemente en las actividades transables, afectando su rentabilidad. Sin embargo, no sufrieron efectos adversos sectores como la minería, los hidrocarburos y la pesca, cuya rentabilidad depende más de las características del recurso natural que valorizan.

\section{$\mathrm{V}$}

\section{Tipo de cambio real y competitividad}

En la actualidad, tiende a predominar la idea de que el tipo de cambio real multilateral debería permanecer estable. De hecho, a partir de 1994 ha permanecido relativamente estable, aunque con fluctuaciones, excepto en 2003. En este año, como se dijo antes, la devaluación del dólar incidió en el tipo de cambio real, al lograr el BCRP acompañar el descenso del dólar respecto de las demás divisas.

Son varias las razones que explican la estabilidad del tipo de cambio real. Entre ellas cabe destacar las siguientes: i) cuando a principios del decenio de 1990 se abrió la economía, el BCRP estaba batallando por controlar una hiperinflación y el rezago cambiario era usado con ese fin; ii) en 1990-1998, el BCRP asumió que la mejora de la competitividad, como sostenía el gobierno, descansaba en la reducción de los costos laborales y el mejoramiento de la infraestructura, y no en el tipo de cambio real; iii) la economía peruana se caracteriza por generar divisas a través de la gran producción primaria extractiva tradicional y de los cultivos y actividades ilegales, por lo que el tipo de cambio que equilibra las cuentas externas tiende a ser inferior al 
necesario para alcanzar una alta rentabilidad en sectores transables no extractivos; iv) en el decenio de 1990 se instaló en la cultura empresarial y técnica especializada la meta de un tipo de cambio real estable, pero no se analizó en qué grado éste era competitivo ni se tuvo en cuenta la caída que había tenido en 1980-1992; v) hacia fines del decenio de 1990, el elevado endeudamiento privado y público en divisas generó un escenario en el que una devaluación real podía causar pérdidas instantáneas en muchas empresas, elevar el costo fiscal de servir la deuda pública externa y debilitar gravemente la confianza en el país; vi) el síndrome recesivo que afecta a las decisiones de inversión de muchas empresas conduce a una demanda de divisas más débil, y vii) el ingreso de divisas en cuentas financieras sólo se reguló a principios de 2004.

Los factores señalados no justifican la omisión de un régimen de tipo de cambio real competitivo. Pero explican por qué en la práctica el BCRP tuvo que estar muy activo en el mercado de divisas para impedir que cayera el tipo de cambio real bilateral con el dólar. De hecho, en 2002, 2003 y los primeros meses de 2004 dicho banco compró grandes cantidades de divisas, en términos netos, las que constituyeron una proporción muy elevada de las reservas internacionales. Y en marzo del 2004 tuvo que adoptar, por vez primera desde la implantación de la apertura financiera, una regulación de la cuenta de capital, estableciendo un encaje de $20 \%$ sobre los créditos externos.

No obstante, lo principal es que no es factible modificar aisladamente la política cambiaria. Habría que modificar el régimen macroeconómico en su conjunto, alineando las políticas monetaria, fiscal y cambiaria, para defender no sólo una meta de inflación, como se hace en la actualidad, sino además una meta de tipo de cambio real competitivo y estable. ${ }^{4}$ Sólo se puede alcanzar y sostener un tipo de cambio real competitivo si se coordinan estrechamente las políticas cambiaria, monetaria y fiscal para perseguir los dos

${ }^{4}$ Frenkel (2004), Ball (1998), Rodrik (2003) y Williamson (2003). objetivos intermedios señalados, y si se utiliza un instrumental no ortodoxo para regular los grandes movimientos de capital de corto plazo y, en situaciones críticas, evitar la fuga de divisas. Por definición, siguiendo a Frenkel (2004), el carácter expansivo de la política macroeconómica en una economía pequeña, abierta y endeudada con el exterior descansa en un tipo de cambio real competitivo, y no en las políticas monetaria y fiscal. ${ }^{5}$ Por consiguiente, aunque sería deseable un alza gradual del tipo de cambio real, en Perú esto sólo sería viable si se modificara el régimen macroeconómico en su conjunto y no sólo la política cambiaria. Y un cambio de esa profundidad es menos esperable en las presentes circunstancias, pues la estrategia predominante es la inversa: estabilidad del tipo de cambio real a un nivel no competitivo y rol expansivo de las políticas monetaria y fiscal.

Hay que recordar que el rezago cambiario afecta no sólo a la producción exportable, sino también a la producción que compite con las importaciones, está orientada al mercado interno y es una gran generadora de empleo.

A falta de un alza del tipo de cambio real, la mejora de la competitividad dependerá enteramente de la reducción de costos unitarios y/o del aumento de la productividad total a nivel microeconómico. Un incremento esperado muy lento o nulo en dicho tipo de cambio ejerce una presión adicional sobre el ritmo de crecimiento de la productividad total, que debería acelerarse para mejorar la competitividad en un mundo en que muchos países devalúan y todos se esfuerzan por mejorar esa productividad.

\footnotetext{
${ }^{5}$ Siguiendo a Frenkel (2004), diremos que un régimen de tipo de cambio real competitivo y estable contribuye a aumentar el empleo por tres vías: i) a través del aumento a mediano plazo de las exportaciones netas, de la inversión y de la tasa de crecimiento, inducido por la mayor rentabilidad de los sectores transables; ii) por el alza en la elasticidad empleo-producto debido al abaratamiento del componente nacional y de la fuerza de trabajo, y al mayor costo de los componentes importados y equipos (que incide en los sectores transables y no transables), y iii) por la función preventiva frente a los impactos de perturbaciones externas, típica de un régimen de tipo de cambio real competitivo y estable que reduce las pérdidas de empleo provocadas por choques externos.
} 


\section{VI}

\section{Costos laborales medios frente}

\section{a costos totales unitarios}

En el decenio de 1990 se buscó elevar la competitividad a través de mejoras de la infraestructura y, principalmente, de la reducción de los costos laborales medios. Se entiende por costo laboral medio el costo laboral total por unidad de trabajo, y por costo laboral unitario el costo laboral total por unidad producida.

El ajuste a la crisis de la deuda externa de principios de la década de 1980, así como el impacto de la hiperinflación en 1989-1990, hicieron caer las remuneraciones reales en un $65 \%$. Por consiguiente, la apertura comercial de comienzos del decenio de 1990 se apoyó en un costo laboral muy bajo, y a lo largo de ese decenio las remuneraciones medias se fueron recuperando muy lentamente: en 2000 aún eran $40 \%$ más bajas que en 1980 .

Si bien hubo un descenso de los sobrecostos ${ }^{6}$ laborales no salariales y se redujo la indemnización por despido, la vía principal para aminorar los costos en la década de 1990 fue la reforma laboral y las conductas que ella indujo. Al introducir la flexibilidad contractual - múltiples contratos más baratos que los contratos estables-y reducir de hecho la capacidad de negociación de los trabajadores, la reforma laboral influyó directamente en los costos laborales medios; pero además provocó conductas desreguladoras que también afectaron a dichos costos (gráfico 2).

El camino que se adoptó fue principalmente el de trasladar una proporción mayoritaria de los asalariados a contratos más baratos. Según Martínez y Tokman (1999), hacia 1996 el costo laboral de un asalariado estable en la industria era de 2,1 dólares por hora, pero se reducía a 1,37 dólares para el que tenía contrato de corto plazo y a 1,1 dólares para aquel sin contrato. ${ }^{7} \mathrm{El}$

\footnotetext{
${ }^{6}$ En Perú, los sobrecostos laborales se definen como todas las partidas que se agregan al costo salarial para estimar el costo laboral que enfrentan las empresas. Incluye la imputación por vacaciones, y feriados, el impuesto de solidaridad sobre la nómina salarial, el aporte empresarial para la compensación por tiempo de servicio, los aportes para el pago del seguro de salud ocupacional y accidentes del trabajo, y otros componentes del costo laboral no salarial. ${ }^{7}$ Los asalariados sin contrato se definen estadísticamente como aquellos que, según las encuestas de hogares, no registran un contrato laboral ni contribuciones para seguridad social, salud o pensiones.
}

gráfico 2 muestra que entre 1991 y 2001 aumentó a $32 \%$ la proporción de asalariados con contratos temporales (flexibles), como cabía esperar después de la reforma. Pero, paradójicamente, se acrecentó mucho más la proporción de asalariados sin contrato, que se elevó a 47\% en 2000.

La fuerte alza en la proporción de asalariados sin contrato en el sector privado se debió al aumento de la evasión - para reducir costos- y al crecimiento en la década de 1990 de la proporción de asalariados de empresas pequeñas y microempresas en el total de asalariados privados. En estas empresas la evasión tiende a ser mayor que en las medianas y grandes.

Como resultado de estas tendencias, el empleo con contratos estables descendió a un $21 \%$ de la ocupación asalariada privada en 2000: un 79\% de los asalariados en el sector privado del país tenían contratos de corta duración o no tenían contrato.

El traslado masivo de asalariados a contratos menos onerosos redujo en $14 \%$ los costos laborales medios, lo que equivalió a un descenso de una sola vez de 4,7\% en los costos totales unitarios (García, 2002a). Por lo tanto, aun cuando fue una válvula de escape, la baja de los costos laborales resultó del todo insuficiente para

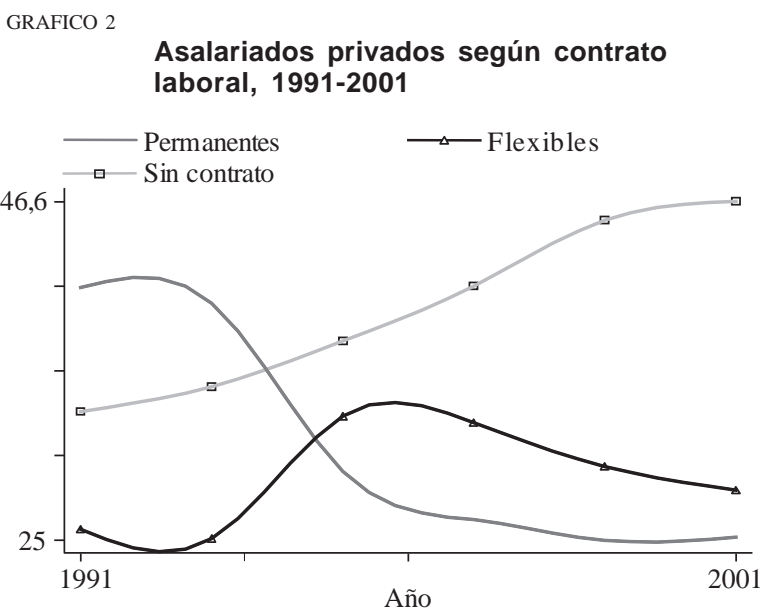

Fuente: Chacaltana y García (2002); Instituto Nacional de Estadística e Informática (INEI), Encuesta Nacional de Hogares, tercer trimestre (varios años) 
compensar las presiones generadas por la caída del tipo de cambio real, la reducción de la protección arancelaria y de los controles, y el estancamiento de la productividad.

La reducción de los costos laborales medios dio pie a un considerable aumento del trabajo precario, y a una conflictividad laboral larvada que se hizo manifiesta en los primeros años de los gobiernos de transición y democrático. Esto último, como quedó demostrado en 2002 y 2003, creó un grave problema al incipiente modelo exportador.

En esencia, ese problema no es sólo de justicia social, sino también de eficacia económica. En contraste con la escasa reducción de costos unitarios que puede obtenerse mediante una conflictiva reducción de los costos laborales, un aumento sostenido de la productividad de 2 a $4 \%$ anual genera una disminución de los costos unitarios de cerca de $25 \%$ en siete años. La baja de los sobrecostos laborales puede contribuir, pero no es la base principal para un aumento significativo de la competitividad a mediano plazo.

La reducción de los sobrecostos laborales es insuficiente: i) porque los costos laborales unitarios son una fracción pequeña de los costos totales unitarios, dada la drástica caída de las remuneraciones como proporción del PIB en 1980-2000; y ii) porque con una gran reducción de los sobrecostos laborales se puede lograr un descenso de una sola vez de $7 \%$ a $8 \%$ de los costos laborales medios, lo que equivale a una disminución de una sola vez de cerca de 3\% de los costos totales unitarios. Esto da una idea de lo que puede lograr esta estrategia.

Lo expuesto hasta acá sugiere que hacia el futuro la estrategia de competitividad basada en la reducción de los costos laborales tenderá a agotarse. En cambio, una estrategia que se asiente en el aumento sostenido de la productividad total para bajar los costos totales unitarios y mejorar la calidad del producto tiene mayor viabilidad sociopolítica, porque las mejoras de la competitividad no se obtienen a expensas de alguno de los actores y, sobre todo, son compatibles con el alza a largo plazo de las remuneraciones reales, al ritmo que permita el respectivo crecimiento de la productividad.

El tema, entonces, no es sólo la reducción de los costos laborales medios y los sobrecostos laborales, enfoque simplificado que se utilizó en el pasado reciente y que perdura en la actualidad. De lo que se trata es de cómo llevar a la práctica con rapidez un esfuerzo sostenido por elevar la productividad de todos los recursos a nivel de las empresas, y lograr así reducciones persistentes de los costos totales por unidad producida y mejoras de calidad. En Martínez y Tokman
(1997) se plantea como alternativa el aumento de la productividad del trabajo para reducir los costos laborales por unidad en dólares, con el fin de elevar la competitividad. En García (2002a) y en este artículo se hace hincapié en el incremento de la productividad total para reducir los costos totales unitarios en dólares a nivel microeconómico incluyendo los del entorno y la infraestructura para facilitar la inversión, así como el alza del tipo de cambio real para lograr la reducción de los costos en divisas. Por consiguiente, en esta propuesta el menor costo laboral proviene del aumento de la productividad laboral, pero éste no es el único factor de reducción de los costos totales unitarios, ya que por definición el aumento de la productividad total implica prestar atención a todos los principales componentes de los costos totales unitarios, y el alza del tipo de cambio real disminuye el costo en divisas.

Los costos totales por unidad producida a nivel microeconómico pueden verse como la suma de los insumos necesarios por unidad de producto multiplicados por el precio de cada insumo. Reducir el conjunto de coeficientes de requerimientos de cada tipo de insumo por unidad de producto (o aumentar la productividad de cada insumo) es la principal vía para disminuir a mediano plazo los costos totales unitarios y mejorar la calidad a nivel microeconómico. Esto equivale a plantear que el descenso de los costos totales unitarios depende del aumento de la productividad de todos los insumos — productividad total - a nivel microeconómico.

Una manera de incorporar como objetivo de la política económica el aumento requerido de la productividad total es suponer que con una política macroeconómica de corto plazo "correcta", en sucesivos cortos plazos, el proceso de ajuste a largo plazo de los mercados generará espontáneamente un aumento sostenido de la productividad total. No obstante, Katz (2000), García (2002a) y Porter (2003) señalan que en los actuales procesos de modernización productiva son indispensables acciones y políticas deliberadas a nivel microeconómico, y no sólo macroeconómico, para inducir procesos exitosos de modernización y de mejora de la productividad. No basta con aplicar políticas macroeconómicas, porque ellas implican plazos más largos y, por su situación social, Perú no dispone de tanto tiempo. Se torna así impostergable la adopción de políticas que incidan significativamente, a nivel microeconómico, en una mayor productividad total de las empresas y el mejoramiento de su entorno.

Este enfoque no ignora la necesidad de transformar a los segmentos más atrasados, en áreas rurales o en actividades informales, aun cuando no es ese el tema 
del presente trabajo. Pero para transferir recursos hacia esos segmentos con el propósito de mejorar significativamente su productividad y sus ingresos, es indispensable que los sectores más modernos puedan crecer a ritmos muy elevados, que permitan una mayor transferencia de recursos. De otro modo, las transferencias para elevar la productividad de los segmen- tos rezagados continuarán siendo relativamente muy débiles, como lo han sido en los últimos 30 años. Para acelerar el crecimiento de los segmentos modernos es imprescindible elevar la productividad total de las actividades transables no extractivas y establecer un régimen macroeconómico de tipo de cambio real competitivo y estable.

\section{VII}

\section{El crecimiento de las exportaciones y el empleo}

No obstante, cabe destacar que una mayor productividad total puede hacer más competitivo al país, pero no garantiza por sí sola que aumente el empleo de calidad. Para lograr esto último es imprescindible combinar las políticas destinadas a elevar la productividad con las medidas orientadas a impulsar decididamente la ampliación de mercados externos y promover las exportaciones.

En un país pequeño, con tres cuartas partes de su población activa ocupada en actividades de muy poca productividad o desocupada, no existe un mercado interno dinámico que pueda impulsar decisiones de inversión privadas en un contexto de economía abierta. Si el tipo de cambio real se eleva a mediano plazo, cabe esperar un mejor desempeño de las actividades que compiten con las importaciones. Pero en ausencia de un tipo de cambio real alto, es difícil que las actividades de sectores transables orientadas hacia el mercado interno puedan contribuir mucho a acelerar el crecimiento, antes de que los efectos del aumento de la productividad en sectores exportables contribuyan a dinamizar dicho mercado.

Es preciso entonces aplicar un conjunto de medidas destinadas a eliminar los obstáculos a las exportaciones, obtener su diversificación, y lograr que crezcan a tasas muy superiores al aumento de la productividad, es decir, a tasas sostenidas de 8 a $9 \%$ anual durante plazos prolongados. Para alcanzar el efecto buscado en el empleo, el incremento de las exportaciones deberá preceder, y después acompañar, el aumento de la productividad total.

Es útil recordar aquí que el punto de partida es el retraso absoluto y relativo de Perú en materia de exportaciones. En 2001, sus exportaciones per cápita a precios constantes eran inferiores a las registradas en 1975, y a principios del siglo XXI, lo mismo que 50 años atrás, en las exportaciones peruanas siguen predominando (casi con 70\%) los productos primarios, principalmente minerales y metales.

Además, las exportaciones se encuentran muy concentradas en tres sentidos (Aráoz, 2002): i) el 68\% corresponde a productos tradicionales, como mineros, pesqueros, hidrocarburos y productos agrícolas, aun cuando estos últimos han declinado mucho y representan sólo un 5\% de las exportaciones tradicionales; ii) el 25\% se destina a los Estados Unidos, el 24,9\% a tres países de la Unión Europea y Suiza, y el 15\% a cinco países de América Latina (Brasil, México, Colombia, Chile y Venezuela); y iii) el $95 \%$ es generado por el $12 \%$ de las empresas exportadoras. En consecuencia, la política debería orientarse a diversificar las exportaciones por tipo de bienes, mercados de destino y empresas que las generan.

En la actualidad hay ocho mecanismos principales para acelerar las exportaciones: i) la negociación de acuerdos de comercio, en los que se viene avanzando con la firma del Acuerdo de promoción comercial andina y erradicación de la droga (ATPDEA) con los Estados Unidos, la ya inminente negociación con Brasil y el Mercosur y las negociaciones en marcha con los Estados Unidos, la Unión Europea, Japón y China; ii) el acceso al crédito previo y posterior al embarque y la difusión de los respectivos seguros y fianzas; iii) la difusión de normas de calidad y tipificación de productos; iv) la identificación de mercados, nichos y estándares para productos exportados, lo que exigirá una estrategia público-privada más potente de la que se ha venido desarrollando; v) la difusión a la mayoría de las 
empresas de prácticas de gestión de la productividad y la calidad, que hoy están circunscritas a unas 400 empresas extranjeras y grandes empresas nacionales; vi) la reducción y mayor homogeneidad de los aranceles, que han sufrido importantes modificaciones de 1992 en adelante ; vii) el desarrollo de la infraestructura productiva, lo que implica promover la aceleración de concesiones al sector privado; y viii) la eliminación de los obstáculos para el desarrollo del sector turismo.

Aráoz (2002) nos recuerda que en 1993-2002 hubo ocho reformas sustantivas al régimen arancelario, que desembocaron en una baja de la tasa media original $\mathrm{y}$, lo que es más importante, en una fuerte variación entre las tasas específicas por tipo de bienes. Hacia fines de 2002, el arancel medio, ponderado por las importaciones, se había reducido a 10,8\%, pero en cambio había aumentado a casi $32 \%$ el coeficiente de variación de la distribución de los aranceles. Además, existen sobretasas temporales a la importación ("salvaguardas") establecidas apresuradamente en 2003 para contener las importaciones de China y otros países asiáticos. Las modificaciones señaladas no responden a un programa, sino a decisiones puntuales que apuntan a disminuir el costo de importar insumos intermedios y bienes de capital o a elevar el costo de productos de consumo, y reflejan iniciativas para beneficiar por esta vía a los productores locales, dado que no pueden lograrlo a través del tipo de cambio real. Por consiguiente, de manera paradójica, un tipo de cambio real estable se ha asociado últimamente a una política de tasas y sobretasas arancelarias variables para ganar competitividad por esta segunda vía.

Respecto a infraestructura, el Instituto Peruano de Economía estimó en 2002 el monto de la inversión necesaria para llevar la infraestructura de puertos, aeropuertos, comunicaciones, autopistas, caminos, energía, etc., al nivel que actualmente se registra en Colombia o Chile (IPE, 2002a y 2002b).

Para contar en 2014 con una infraestructura similar a las existentes en Chile y Colombia en 2002, se requerirá en el decenio una inversión de unos 18.200 millones de dólares, equivalente a 3\% del PIB durante 10 años. Puesto que el sector público carece de los recursos financieros, humanos y materiales necesarios para encarar este desafío, es indispensable desarrollar con rapidez una estrategia de concesiones al sector privado, inexplicablemente detenida en los últimos cuatro años.

Una estimación conservadora efectuada para este trabajo sugiere que una inversión en infraestructura de 18.200 millones de dólares se traduciría en la creación directa de aproximadamente 200.000 puestos de trabajo de un año de duración media, distribuidos en diez años, y la creación indirecta de alrededor de 500.000 puestos de trabajo, estos últimos con algún rezago. Esto indica que al fomentar la inversión privada en infraestructura pública que contribuya a mejorar la productividad de las empresas no sólo se genera empleo por la mayor competitividad que se confiere a esas empresas, sino también porque la construcción misma de infraestructura da origen a una gran cantidad de empleo directo e indirecto. Se trata, por lo tanto, de una actividad a la que debería darse prelación.

Respecto al sector turismo, su desarrollo es prioritario por tres razones: i) cuenta con un enorme potencial para generar divisas; ii) tiene un elevado efecto directo e indirecto sobre el empleo; iii) es un sector en el que no existen barreras de entrada relacionadas con el conocimiento y grandes innovaciones, porque las características técnicas y de organización de las diferentes actividades que lo componen son ya conocidas y dominadas en el país.

Según Chacaltana (2002), el desarrollo del turismo en Perú se aceleró en 1992-1998, período en que el número de turistas se triplicó. En 1998 los turistas fueron 600.000 y los ingresos de divisas llegaron a 920 millones de dólares. En la actualidad, pese a las dificultades planteadas por el conflictivo escenario internacional, el número anual de turistas supera los 900.000 , y los ingresos de divisas por este concepto se han elevado proporcionalmente.

Hacia fines del decenio de 1990, y sin que existiese una política activa para impulsar este sector, el turismo aportaba $40 \%$ por ciento de las divisas que generaban las exportaciones no tradicionales. Por su parte, entre 1992 y 1998 el empleo vinculado a actividades turísticas creció muy rápidamente, a una tasa anual de 15\%. En 2000 el nivel de empleo del sector turismo era similar al del sector de la construcción y equivalente a $40 \%$ del de la industria manufacturera, aunque el desarrollo turístico era aún incipiente después de muchos años de estancamiento, y el tipo de cambio real no era favorable. De otra parte, como el turismo es un generador neto de divisas, contribuye por esa vía a la generación indirecta de empleo en otros sectores. Por consiguiente, su potencialidad para incidir en la creación de empleo es igual o mayor que la de la construcción, con la ventaja sobre esta última de ser un sector transable que contribuye a mejorar la balanza de pagos. Todo lo anterior apunta a la necesidad de políticas que fomenten el desarrollo del sector a través de mejoras de la seguridad personal y de la 
infraestructura turística en distintas zonas del país, la colocación de paquetes turísticos mayoristas, la diver- sificación de la actividad turística hacia el Amazonas, el desarrollo del turismo de aventura y otras medidas.

\section{VIII}

\section{La capacitación, la flexibilidad laboral y la productividad}

En línea con los planteamientos teóricos de Amadeo y Camargo (1996), la evidencia empírica acerca de la industria manufacturera peruana - cuyo perfil se acerca al perfil medio del sector transable - sugiere que el fuerte aumento de la inestabilidad contractual reduce los costos laborales medios, pero inhibe el aumento de la productividad laboral. En consecuencia, el efecto neto sobre los costos laborales unitarios es inferior al que se aprecia si se observan sólo los costos laborales medios. La razón es simple: la mayor inestabilidad laboral inhibe el gasto en capacitación que hacen las empresas y, de ese modo, afecta el incremento de la productividad laboral (Chacaltana y García, 2002).

Una fuerte dosis de inestabilidad contractual -que como se vio en una sección anterior, en 2000 afectaba al $79 \%$ de los asalariados del sector privadogenera, por el temor a la pérdida del empleo, un aumento de la intensidad del trabajo y una mayor productividad laboral. Pero, por otro lado, desincentiva el gasto en capacitación que efectúan las empresas, ya que en estas circunstancias se hacen menos proclives a invertir en capital humano y prefieren captar trabajadores capacitados de otras empresas. El efecto neto de una mayor inestabilidad laboral sobre la productividad es, por lo tanto, un tema empírico.

Chacaltana y García (2002) encontraron que las empresas manufactureras de Perú con una mayor proporción de contratos laborales inestables tienen $28 \%$ menos probabilidades de invertir en capacitación que aquellas con una mayor proporción de empleo estable. También comprobaron empíricamente que las empresas que capacitan generan $25 \%$ más valor agregado que aquellas que no lo hacen, considerando otras variables como tamaño del negocio, nivel de activos y rama de actividad. Asimismo, encontraron una elasticidad (productividad laboral en la empresa/gasto en capacitación de la empresa) cercana a 0,10. Esto es, una reducción (aumento) de $50 \%$ en el gasto en capacitación de la empresa genera una caída (elevación) de 5\% en su productividad laboral. Por lo tanto, el efecto que pre- domina es el impacto neto negativo sobre la productividad.

La evidencia empírica, por lo tanto, apunta a una connotación de política nada trivial: en la medida en que predomine el efecto adverso sobre la productividad laboral, la reducción de costos laborales medios provocada por un incremento significativo de la flexibilidad contractual es parcialmente neutralizada por el efecto adverso de esa flexibilidad sobre los costos laborales unitarios, causado por un menor crecimiento de la productividad.

En Perú, la reforma laboral buscó aminorar los costos laborales medios por hora y facilitar el manejo de la mano de obra. Pero al hacerlo, ignoró sus repercusiones sobre la capacitación y la productividad. La falta de capacitación se transformó así en una restricción para el aumento de la productividad total.

Según Chacaltana y García (2002), la evidencia presentada plantea también una suerte de paradoja conceptual. Para movilizar la inversión privada se necesita cierto margen de flexibilidad respecto de la mano de obra. Sin embargo, si esa flexibilidad es demasiado extrema - como parece haber sucedido en el caso peruano- empiezan a surgir desincentivos para la capacitación y, por ende, obstáculos al aumento de la productividad y la competitividad.

¿Cómo compatibilizar la dosis necesaria de flexibilidad en el mercado laboral y la también necesaria inversión en el capital humano de los trabajadores que, como ya se dijo, genera mayor productividad en las empresas?

Existen al menos tres alternativas, no excluyentes. La primera es capacitar a través de un sistema público de capacitación, de amplio acceso, fuerte incidencia y costo nulo para las empresas. Pero esta alternativa supone una enorme disponibilidad de recursos fiscales, que no se concilia con la situación vigente en Perú.

La segunda es hacer que la institucionalidad laboral que establece los plazos y características de los 
contratos laborales tenga en cuenta los plazos necesarios para que una inversión en capacitación brinde una rentabilidad razonable a las empresas. Lo esencial aquí es que la institucionalidad laboral vigente — de hecho y de derecho- no debería incentivar plazos de contratación medios inferiores a los requeridos para que la inversión en capacitación sea rentable. Reducir la duración media de los contratos laborales a pocos meses, en forma generalizada y profunda, equivale a suponer que la inversión en capacitación puede generar en esos pocos meses la rentabilidad que la amortiza, lo que claramente no es realista.

La tercera alternativa es abrir paso a la flexibilidad en las empresas con miras al aumento de la productividad, lo que además de servir de amortiguador ante choques externos, demanda una menor dosis de inestabilidad laboral.

Adicionalmente, Chacaltana y García (2002) hicieron presente un factor relacionado con el contexto económico. En una economía que crece por períodos breves para luego volver a caer en una fase recesiva, son muchas las empresas que no pueden hacer planes de largo plazo. En consecuencia, exhiben en sus negocios tasas de descuento bastante altas, lo que implica desechar todas las inversiones en capacitación cuya rentabilidad sea inferior a esas tasas. Por esta razón, un factor decisivo para inducir a las empresas a invertir más en capacitación y así elevar sistemáticamente la productividad total, es generar expectativas de crecimiento elevado y permanente.

\section{IX}

\section{La apertura y el comportamiento}

\section{microeconómico}

\section{Apertura y crecimiento de la productividad a nivel microeconómico}

La apertura económica debería haber traído consigo aumentos significativos de la productividad total a nivel microeconómico. Es importante reflexionar por qué no sucedió así, para tener en cuenta lo que surja de esa reflexión en el diseño de nuevas propuestas. Al respecto, García (2002b) señala los factores que se enumeran a continuación.

En primer lugar, una economía más abierta ofrece mayores oportunidades de información y conocimiento de innovaciones que una economía más cerrada, y por este motivo, brinda un marco mucho más propicio para el crecimiento potencial de la productividad. Edwards (1998) analizó empíricamente la experiencia de 93 países y concluyó que la productividad total de los factores tiende a crecer con más rapidez en una economía abierta que en una cerrada, porque en la abierta hay mayores posibilidades de absorber el progreso tecnológico generado por los países líderes; aunque no apuntó estrictamente a los factores causales, señaló la necesidad de mayor investigación empírica microeconómica en torno a la apertura y al aumento de la productividad total de los factores. Respecto a esto último, Baily y Solow (2001) elaboraron comparaciones internacionales de la productividad, conceptualmente construidas a partir de la empresa, y concluyeron que la intensidad de la competencia internacional (e interna) impacta fuertemente sobre la productividad. Esto, en el caso de Perú, lleva a preguntarse cuáles son los factores que inhibieron a nivel microeconómico el crecimiento de la productividad total. Sobre este tema se volverá en los párrafos siguientes.

Un segundo aspecto importante es la influencia de un impulso exportador. El aumento de las exportaciones depende de la mejora de la productividad y la competitividad. Pero también es cierto que el énfasis en las exportaciones exige un alineamiento que conduzca a aumentos de productividad. El esfuerzo de exportar demanda menores costos y mayor calidad en materia de productos, conservación, transporte, comunicaciones y entrega. Obliga también a adaptarse a mercados y pautas de países más avanzados. Todo ello repercute en exigencias de mayor productividad y calidad que, a medida que el impulso exportador se diversifique, se irán difundiendo a diferentes ámbitos de la economía. Pero si el impulso exportador queda confinado a los enclaves tradicionales —en Perú, la minería, la pesca industrial y el gas e hidrocarburos-, las presiones que conducen al aumento de la productividad no se difunden. 
El tercer aspecto tiene que ver con la forma en que los empresarios peruanos - muchos de ellos sin experiencia en materia de competitividad externa- percibieron concretamente la mayor competitividad exigida por la apertura. Si el mensaje central para lograr competitividad — como lo fue en Perú en el decenio de 1990 — es el de reducir los costos laborales medios a través de la flexibilización laboral y la reducción de los sobrecostos laborales, no existe relación entre la percepción y la realidad, ya que ni siquiera una fuerte baja de costos laborales medios generaría un descenso apreciable y sistemático de los costos totales unitarios y una mejora de la calidad todos los años. Sólo el aumento permanente de la productividad total puede causar tal descenso. Por consiguiente, el énfasis en la reducción de los costos laborales medios que se registró en la década de 1990 sirvió como medida defensiva, pero también actuó como un "mito", impidiendo que el problema real fuese percibido y colocándolo fuera de la reflexión empresarial. Tal reflexión habría sido necesaria para adoptar estrategias encaminadas a elevar la productividad de las empresas.

Lo expuesto tiene particular relevancia hoy: ¿qué se debe hacer para terminar con el mito y entregar a los empresarios peruanos un mensaje apegado a la realidad que supere las limitaciones de lo planteado en el decenio de 1990? La información sobre índices de competitividad provista por el World Economic Forum confirma lo dicho. En el ordenamiento según el Índice de Competitividad del Crecimiento, que se basa en una muestra de 80 países, Perú bajó de la posición 54 a la 57 en el período 1999-2002. Pero según el Índice de Competitividad Microeconómica, descendió de la posición 47 a la 68 , principalmente por el deterioro del entorno para los negocios y las estrategias de las empresas. $^{8}$

Tomar la decisión de elevar la productividad a nivel microeconómico es importante además desde el punto de vista de la equidad. El crecimiento macroeconómico se difunde más a nivel microeconómico en un proceso con aumento de la productividad que en un ajuste con reducción de costos laborales medios. La razón es simple: el aumento de la productividad permite un alza de las remuneraciones reales, no así la estrategia de reducción de costos laborales.

Un cuarto aspecto es el siguiente: para que la potencialidad que ofrece una mayor apertura se transfor-

\footnotetext{
${ }^{8}$ Véase Cornelius (2003), Porter (2003) y World Economic Forum (www.worldeconomic forum.com).
}

me en un impulso sistemático y permanente hacia el aumento de la productividad, es preciso alinear las decisiones microeconómicas con ese objetivo (Porter, 1998; Katz, 2000). Esto a su vez requiere que el entorno de los negocios (Porter, 2003) y la institucionalidad (Stiglitz, 1998; Katz, 2000) incidan a nivel microeconómico en forma concordante. Quizás lo más significativo sea el mejoramiento del entorno para los negocios y del tejido institucional, con miras a facilitar e inducir decisiones permanentes de elevar la productividad a nivel microeconómico (Porter, 1998; Katz, 2000). Los elementos del entorno microeconómico que deben mejorarse o reformarse se examinan en Porter (2003), mientras en García (2002a) se explora lo relativo a la institucionalidad microeconómica en la experiencia peruana. Una economía de mercado no funciona sin las instituciones correspondientes. De igual manera, un ajuste en la competitividad mediante aumentos de la productividad no se logra —o demora mucho en concretarse - sin una institucionalidad que estimule la adopción de este tipo de decisiones.

Stiglitz (1998) señaló la importancia de aplicar nuevas formas de ingeniería institucional y nuevos modelos de interacción de lo público y lo privado, si se desea dar bases firmes a los nuevos modelos de crecimiento, contribuir a un mayor incremento de la productividad total y lograr más equidad en los procesos de modernización. Porter (2003) describió la mejora del entorno de los negocios y las estrategias de las empresas como factor clave para elevar la competitividad, en tanto que Katz (2000) hizo hincapié además en que es preciso analizar los cambios microeconómicos para entender lo que ha sucedido con el surgimiento de los nuevos modelos abiertos y orientados al mercado.

En quinto lugar, además de generar un entorno y una institucionalidad que faciliten y estimulen el aumento de la productividad a nivel microeconómico, hay que sincronizar las políticas públicas de nivel intermedio con la misma finalidad. El ejemplo típico, ausente en la experiencia peruana de la década de 1990, es la batería de políticas orientadas a mejorar sistemáticamente la capacitación de la mano de obra y su productividad.

\section{El índice de competitividad microeconómica y el aumento de la productividad}

$\mathrm{Al}$ analizar cómo operan las empresas de un país, Porter (2003) señala tres fases. En la primera, típica de los países más pobres (entre los cuales dicho autor clasifica a Perú), la competitividad descansa en la mano 
de obra barata y el uso de los recursos naturales del país, y la tecnología es asimilada vía imitación, importaciones e inversión directa. En la segunda fase, conducida por la inversión y típica de los países de ingreso medio, la competitividad pasa a descansar en las mejoras de la eficiencia para producir bienes y servicios estándares; esta fase se caracteriza por grandes inversiones en infraestructura, una administración preocupada por el desarrollo de las empresas y fuertes estímulos a la inversión privada y a la llegada de capitales, todo lo cual repercute en mejoras de la productividad; los bienes y servicios se tornan más sofisticados, pero el cambio tecnológico sigue viniendo del exterior, pese a que existe la capacidad de adaptar y mejorar la tecnología extranjera. En la tercera fase, típica de los países de altos ingresos, la fuente de competitividad predominante es la habilidad para producir bienes y servicios innovadores, en la frontera tecnológica global, utilizando los métodos más avanzados disponibles; el entorno empresarial se caracteriza por su fortaleza en diversas actividades y por la existencia de cadenas de producción y aglomeraciones productivas (clusters).

Cabe hacer aquí dos comentarios al planteamiento de Porter (2003), dada su relevancia para este trabajo. El primero, que las fases pueden entenderse como procesos en los que ciertos factores gradualmente van ganando masa crítica, o desapareciendo, no como consecuencia de una ley histórica sino por diversas causas, entre las cuales se encuentra la acción de políticas privadas y públicas. Esto significa que pesa y tiene impacto el cambio en las actitudes, ideologías y enfoques respecto al desarrollo de las empresas, proyectados en las reglas que rigen su conducta.

El segundo comentario es que el análisis de Porter (2003) se refiere a países. Pero en muchas de las realidades latinoamericanas, caracterizadas por la convivencia de segmentos modernos con un conjunto de actividades rezagadas o atrasadas, ese análisis sólo es válido para los segmentos modernos de cada país, que son los proclives a invertir y tienen la posibilidad de hacerlo. Sólo para ellos tiene sentido un proceso secuencial de construcción, a nivel microeconómico, de capacidades interdependientes. La heterogeneidad estructural en que hizo hincapié la escuela estructuralista latinoamericana en los decenios de 1960 y 1970, es típica de muchos países de América Latina, donde coexisten persistentemente segmentos modernos y relativamente desarrollados con otros muy rezagados. Esto quiere decir que si se considera el segmento moderno y estructurado del país, para el cual tienen sentido las estrategias de modernización microeconómicas, los factores que influyen en la competitividad, el grado de organización y el PIB per cápita no corresponden al promedio del país en su conjunto. Por consiguiente, son los datos que caracterizan a los segmentos modernos, y no los promedios del país, los útiles para evaluar la estrategia competitiva más apropiada.

Un ejemplo de lo que se viene exponiendo emerge del propio trabajo de Porter (2003), en cuyo gráfico 6 se correlaciona la distribución del Índice de Competitividad Microeconómica por países con la distribución del PIB per cápita por países correspondiente a 2001, ajustado por la paridad de poder de compra. En ese gráfico, Brasil aparece con un Índice de Competitividad Microeconómica ligeramente inferior al de Túnez, mientras que el de México se halla por debajo del de Croacia, Namibia, Jordania y Marruecos. En la práctica, lo que sucede es que los indicadores que constituyen la base de dicho índice son representativos del país en su conjunto, siendo que en el caso de Brasil y México deberían utilizarse los representativos de sus segmentos modernos. Lo mismo ocurre con Perú. Según el gráfico citado, el Índice de Competitividad Microeconómica peruano es inferior al de Jordania, Botswana, Namibia, Vietnam, Marruecos, El Salvador y Túnez, esto porque los indicadores adoptados como base y normalizados para el país son sólo atribuibles al segmento moderno de la economía peruana. Lo mismo pasa cuando consideramos el PIB per cápita de Perú. A fines del decenio de 1990 éste ascendía a aproximadamente 4.650 soles de 1994 (unos 2.400 dólares), pero cuando se intenta una estimación del PIB per cápita del segmento moderno, pertinente para el análisis de la competitividad, el resultado casi triplica dicha cifra. Lo que esto implica es claro: si se considera el PIB per cápita del segmento moderno, Perú clasifica como país de ingreso medio y, por lo tanto, el análisis de Porter lo ubica en la fase en que la conducción de la la inversión debería haber contribuido al aumento de la productividad, y no en la fase en la que la competitividad descansa sólo en mano de obra barata.

Cuando se tiene en cuenta el conjunto de comentarios anteriores, no hay duda de que los segmentos modernos de la economía peruana podrían haber pasado a la segunda fase en la década de 1990. Lo que los frenó fue una visión restrictiva de la competitividad, confinada a la reducción de los costos laborales, que causó graves daños sociales y tuvo consecuencias económicas más graves aún. El tema ahora es cómo cambiar esa visión. 


\section{X}

\section{Las políticas para elevar la productividad total}

En esta sección se pasa revista al tipo de propuestas que ya han sido formuladas para mejorar la productividad total.

Porter (2003) describe un conjunto de factores prioritarios a nivel microeconómico por su efecto sobre la competitividad de las empresas, y los agrupa así: i) factores que determinan el entorno microeconómico, como la infraestructura física — de particular importancia para Perú-, la infraestructura administrativa, la calidad de los recursos humanos, el marco jurídico y judicial, la infraestructura tecnológica, el desarrollo de los mercados financieros, el marco regulatorio de la inversión, los incentivos a la competitividad, las barreras comerciales y la intensidad de la competencia interna; y ii) factores que influyen sobre las estrategias de las empresas, como la naturaleza de la ventaja competitiva, la sofisticación de los procesos productivos, la capacitación del personal, la comercialización, la delegación de decisiones, la penetración en mercados externos, la capacidad de innovación y el uso de la gerencia profesional.

En García (2002a) se plantean cambios en el entorno institucional y económico que influyen en las decisiones microeconómicas, entre ellos los siguientes:

i) Reemplazar gradualmente el modelo predominante de negociación laboral por otro que, además de los temas habituales de poder adquisitivo de los salarios y protección social, incluya:

- aspectos y compromisos de ambas partes que contribuyan a elevar la productividad en la empresa, e

- incentivos salariales a la productividad que permitan vincular los reajustes de salarios reales con aumentos de la productividad.

ii) Desarrollar la institucionalidad necesaria para difundir gradualmente hacia la mediana y pequeña empresa conductas y prácticas encaminadas a elevar su productividad.

iii) Fortalecer y modernizar la fiscalización del cumplimiento de la legislación laboral, para reducir la muy elevada proporción de asalariados sin contrato; es probable que, por razones de eficiencia, esto deba asociarse a la fiscalización del pago de impuestos directos e indirectos por las empresas.

iv) Poner en práctica políticas activas para fomentar y financiar la innovación tecnológica. Puesto que actualmente la mayor parte de los países que compiten con Perú tienen políticas de esta índole, la ausencia de ellas en el ámbito peruano refuerza la tendencia a quedar atrás en materia de aumento de la productividad. Lo que debe hacerse no es abandonar una estrategia basada en recursos naturales valiosos, sino contribuir a darles más valor agregado a esos recursos mediante su elaboración y el estímulo a la innovación. Esto ayudará además a sentar las bases para una evolución gradual hacia un modelo de competencia basado en la innovación, recurriendo a la adaptación de las innovaciones efectuadas en el exterior. Como Perú está inserto en un mundo que se mueve hacia la competencia en productos y servicios que hacen uso intensivo del conocimiento y la innovación, se propone crear un Fondo concursable para innovaciones y otras medidas destinadas a estimular y facilitar la innovación en las empresas, generar masa crítica en centros tecnológicos y universitarios, y, sobre todo, a articular estos segmentos. El Fondo haría préstamos para financiar la etapa inicial de desarrollo y prueba de las innovaciones.

v) Impulsar un mercado de servicios de capacitación y establecer un marco regulatorio para él. Con ese propósito se propone lo siguiente: crear un Consejo nacional de formación y establecer por ley un marco que regule el mercado de servicios de capacitación y formación; establecer un Fondo nacional para la formación; estimular el desarrollo de oferentes de calidad para este mercado; orientar este mercado hacia la formación por competencias; establecer un sistema de certificación de calidad de los oferentes de servicios de capacitación; desarrollar un método para evaluar y certificar la pertinencia de los oferentes y de sus servicios; hacer mucho más uso de la formación en la empresa y ayudar a difundir prácticas que eleven la productividad; establecer incentivos fiscales para que las empresas inviertan en formación 
laboral y fortalecimiento de la gestión de la productividad y la calidad; y, siguiendo a Sierra y Sato (2002), ampliar los recursos destinados a subsidiar los "bonopymes" con miras a cofinanciar los servicios de capacitación orientados a la pequeña y mediana empresa, pero focalizando su uso en la gestión de la productividad. Según Chacaltana y García (2002), la capacitación en la empresa contribuye significativamente a elevar la productividad a nivel microeconómico. En rigor, no se trata sólo de mejorar la capacitación en la empresa, sino también de que ésta adopte nuevas prácticas laborales y una concepción más avanzada de la gestión de los recursos humanos, que acreciente la comunicación con los trabajadores, que haya formación permanente y que todo ello se traduzca en incentivos salariales. Todo esto, junto con más capacitación en la empresa, es lo que redunda en alzas significativas de productividad. $^{9}$

\section{XI}

\section{Conclusiones}

Este artículo hace hincapié en que el concepto de una competitividad basada en la reducción de los costos laborales medios, que fue promovido en el decenio de 1990 y persiste hasta hoy en Perú, no sólo no contribuyó a generar una rentabilidad suficiente para inducir un aumento sostenido de la inversión privada en sectores transables, sino que ocultó la necesidad de elementos esenciales para mejorar la competitividad de las empresas peruanas: i) un tipo de cambio real competitivo y estable en la fase de ignición, y ii) un crecimiento sostenido de la productividad total a nivel microeconómico. Lo que se enfrenta ahora es cómo reorientar gradualmente el régimen macroeconómico y las decisiones microeconómicas en las direcciones expuestas. Es en este contexto que conviene situar las siguientes conclusiones.

\section{La competitividad, el tipo de cambio real y la productividad total a nivel microeconómico}

A partir de fines de la década de 1970, la productividad dejó de ser una variable exógena y se transformó

\footnotetext{
${ }^{9}$ Véase Ichniowski, Shaw y Prennushi (1995).
}

vi) Fomentar la articulación de las pequeñas y medianas empresas en aglomeraciones (clusters) o cadenas productivas, o su vinculación con redes productivas lideradas por empresas mayores, como lo exige el actual desarrollo de las pymes. Todos estos lazos, unidos a un mayor acceso a los recursos, contribuyen a elevar su productividad, de modo que la eliminación de los obstáculos para desarrollar tales aglomeraciones, cadenas o redes productivas es una vía muy eficaz para mejorar la competitividad de las pymes que las integran. El Gobierno de Perú ya está poniendo en marcha iniciativas en esta dirección, y sería muy positivo que las profundizara, facilitando sistemas mancomunados de información sobre los mercados, los proveedores, los sistemas de benchmarking y las mejores prácticas entre las pymes. Estas medidas tienen mucho más trascendencia de lo que parece, puesto que la mayor parte de las empresas de Perú son pequeñas o medianas.

cada vez más, de manera paulatina, en una variable de política, susceptible de modificarse positivamente mediante acciones privadas y públicas. Esto ocurrió tanto en las economías desarrolladas como en las emergentes, aunque de distinta manera. En un escenario como el actual, caracterizado por la revolución tecnológica y organizacional más profunda de la historia, esa posibilidad de influir condujo gradualmente a la aceptación generalizada de que, en un entorno globalizado, las mejoras de la competitividad dependían del aumento de la productividad total.

Dos cosas sobresalen en este contexto. La primera es que para promover aumentos de productividad a nivel microeconómico es preciso que en las empresas haya propensión a invertir (en innovaciones, capacitación, equipos, etc.), particularmente en sectores transables. Un régimen macroeconómico de tipo de cambio real competitivo y estable durante la larga fase de ignición, puede asegurar la rentabilidad necesaria para acelerar decisiones de inversión en esos sectores.

La segunda es que un régimen de esa índole debe servir para dar tiempo al proceso de maduración que se necesita para que hagan sentir sus efectos las políticas de aumento de la productividad total a nivel microeconómico. 
Para definir apropiadamente el criterio de competitividad que corresponde a un país como Perú, no se puede desestimar que en él, como en muchos otros países de América Latina, persiste la convivencia de segmentos modernos, y relativamente desarrollados, con segmentos muy rezagados. Esto quiere decir que cuando se consideran estrategias de modernización microeconómica que tienen sentido para los segmentos modernos y estructurados del país, son los datos de estos segmentos, y no los datos medios del país, los que permiten evaluar la estrategia de competitividad más apropiada. Es por este motivo que puede rechazarse la reducción de los costos laborales como única vía para elevar la competitividad, y aceptarse lo que ha sido una tesis central de este trabajo: que la competitividad mejora con el aumento de la productividad total a nivel microeconómico, en el contexto de lo que Porter (2003) denomina fase de la economía conducida u orientada por la inversión.

El enfoque propuesto de tipo de cambio real competitivo y estable y de aumento de la productividad total microeconómica no invalida el aporte que puede hacer la reducción de los sobrecostos laborales, pero lo sitúa en una dimensión realista.

\section{El tipo de cambio real, la productividad, las exportaciones y el empleo}

Un tipo de cambio real competitivo en la fase de ignición y el aumento sostenido de la productividad total en sectores transables a nivel microeconómico son la base de la competitividad. Pero para que el empleo de calidad crezca a las tasas deseadas, la demanda de productos transables y no transables debe crecer con mucho más rapidez que la productividad. Con un tipo de cambio real competitivo y estable, el aumento de la demanda descansa inicialmente en el crecimiento de las exportaciones y de la producción que compite con las importaciones. Por lo tanto, para avanzar más rápido en este campo se necesitan políticas que fomenten las exportaciones y también convenios comerciales. El aumento de la producción e inversión en los segmentos transables contribuirá paulatinamente a dinamizar, de manera directa e indirecta, la demanda interna de bienes sustitutivos de las importaciones. Con esto el grueso de la inversión en sectores transables podrá crecer a una tasa elevada y, si se aplican políticas de articulación apropiadas, inducir a nivel agregado un ritmo más rápido de crecimiento económico y un incremento significativo del empleo de calidad en los segmentos modernos. A su vez, el alza en el em- pleo y los salarios (en estos últimos por las mejoras de productividad) dinamiza la demanda interna. En consecuencia, la mejor política de empleo es combinar las medidas encaminadas a sostener un tipo de cambio real competitivo y estable, a elevar la productividad total a nivel microeconómico y a mejorar la calidad del producto, por un lado, con medidas orientadas a acelerar aún más el crecimiento de las exportaciones, por el otro.

\section{La institucionalidad microeconómica}

Para aprovechar el acceso a innovaciones que ofrece una economía abierta no sólo es preciso aplicar una política macroeconómica "correcta", sino también generar un entorno microeconómico apropiado y, sobre todo, establecer un contexto institucional que facilite la adopción de innovaciones a nivel microeconómico. Dicho de otro modo, es imprescindible un contexto institucional (entendido como un conjunto de reglas del juego que rigen la conducta de las empresas) que incida a nivel microeconómico y que induzca en ese nivel a la adopción de políticas para elevar la productividad.

Un corolario importante de lo expuesto es que el sistema institucional de incentivos no debería obstaculizar la adopción de estrategias microeconómicas para mejorar la productividad, como lo hizo la institucionalidad laboral peruana en la década de 1990, al sesgar las estrategias microeconómicas hacia la reducción de los costos laborales medios y borrar de la agenda empresarial el aumento de la productividad total.

\section{La flexibilidad del mercado laboral y la flexibi- lidad para elevar la productividad}

En 1990-2003, la reforma laboral peruana y la reacción pendular a décadas de protección laboral llevaron a conductas que de hecho fueron más allá de lo que la reforma planteaba. Sea por ingenuidad de los responsables de las políticas, sea por prescindencia, el resultado fue un fuerte aumento del empleo precario en el mercado laboral, con un exceso de contratos inestables y desprotegidos, surgidos en su mayor parte al propagarse la contratación "en negro". Esto acrecentó la precariedad laboral y el conflicto social. Asimismo, inhibió el gasto en capacitación de las empresas, lo que pasó a restringir el incremento de la productividad total. Lo grave fue que el énfasis puesto en la reducción de los costos laborales medios impidió reconocer cuáles eran las fuentes reales de competitividad para el 
país. El mayor daño que esto causó fue llevar el debate sobre la competitividad a un ámbito poco relevante, económicamente ineficaz y socialmente conflictivo, y convencer al actor principal, el empresariado peruano, de que era el correcto. De ahí que una de las mayores tareas en adelante sea la de aclarar a los empresarios que el enfoque predominante en el decenio de 1990 debe ser reemplazado gradualmente por una estrategia de aumento de la productividad a nivel microeconómico y mesoeconómico. Esto supone mantener los costos laborales reales alineados con el crecimiento de la productividad microeconómica e instalar un régimen de tipo de cambio real competitivo y estable.

En consecuencia, lo que deberá dilucidar la política económica en este terreno es:

i) qué medidas concretas pueden adoptarse para reemplazar gradualmente la vieja flexibilidad del mercado de trabajo, ya agotada como estrategia de competitividad, e impulsar en cambio la "flexibilidad del proceso productivo para el aumento de la productividad total", bajo el espacio de protección brindado por un tipo de cambio real competitivo y estable durante el período de ignición de esta estrategia; $y$

ii) cómo efectuar el tránsito de uno a otro enfoque de la competitividad, lo que implica combinar empíricamente la flexibilidad difundida para elevar la productividad, por un lado, con el margen de flexibilidad del mercado de trabajo que efectivamente necesitan las empresas, por otro, pues en la práctica la competitividad del país dependerá de esta mezcla.

Sin un régimen macroeconómico de tipo de cambio real competitivo y estable, estrategias microeconómicas de aumento de la productividad y una política agresiva de diversificación de las exportaciones y de suscripción de convenios comerciales, es poco probable que aumenten significativamente la competitividad, la inversión privada y el empleo de calidad.

Lo que se sostiene en este artículo difiere de las recomendaciones predominantes en Perú, que siguen haciendo hincapié en la reducción de los costos laborales medios y que son promocionadas desde dentro y fuera del país. Se plantea aquí que la mejor política de empleo está dada por la voluntad de ampliar y diversificar mercados externos y por la pujanza para mejorar constantemente la competitividad a través de un tipo de cambio real competitivo y estable y del aumento de la productividad, particularmente en el sector transable. Aunque esto puede parecer contradictorio desde una perspectiva económica tradicional, es después de todo coherente con lo que el sentido común nos anticiparía para una economía pequeña y abierta, inserta en un proceso de globalización y en una etapa histórica caracterizada por la calidad y variedad de las innovaciones disponibles.
Amadeo, E. y J.M. Camargo (1996): Labour flexibility, productivity and adjustment, en J.B. Figuereido (comp), Las instituciones laborales frente a los cambios en América Latina, Ginebra, Instituto Internacional de Estudios Laborales (IIES)/Organización Internacional del Trabajo (OIT).

Aráoz, M. (2002): Perspectivas de la política arancelaria y de integración, Economía y sociedad, $\mathrm{N}^{\circ} 48$, Lima, Consejo Interamericano Económico y Social (CIES).

Baily, M. y R. Solow (2001): International productivity comparisons built from the firm level, Journal of Economic Perspectives, vol. $15, N^{\circ} 3$, Nashville, Tennessee, American Economic Association.

Ball, L. (1998): Policy Rules for Open Economies, NBER Working Paper, $\mathrm{N}^{\circ}$ 6760, Cambridge, Massachusetts, National Bureau of Economic Research (NBER).

CAF (Corporación Andina de Fomento) (2002): Obstáculos al aumento de la productividad en el Perú, Caracas, documento interno.

Cornelius, P. (2003): Growth Competitiveness Report, 2003, www.worldeconomicforum.org.

Chacaltana, J. (2002): El desarrollo del sector turismo y el empleo, Red de políticas de empleo, Lima, Consejo Interamericano Económico y Social (CIES).

Chacaltana, J. y N. García (2002): Estabilidad laboral, capacitación y productividad, Red de políticas de empleo, Lima, Consejo Interamericano Económico y Social (CIES).
De Ferranti, G. y otros (2003): Cerrando la brecha en educación y tecnología, Washington, D.C., Banco Mundial.

Edwards, S. (1998): Openness, productivity and growth: what do we really know?, The Economic Journal, vol. 108, № 447, Oxford, Blackwell Publishing, marzo.

Frenkel, R. (2004): La política macroeconómica para el crecimiento y el empleo, Estrategia de crecimiento y empleo en el Mercosur, Lima, Organización Internacional del Trabajo (OIT), abril, versión preliminar.

García, N. (2004): Estrategia de crecimiento y empleo: el enfoque, Estrategia de crecimiento y empleo en el Mercosur, Lima, Organización Internacional del Trabajo (OIT), abril, versión preliminar.

(2002a): Productividad, competitividad y empleo, Lima, Consejo Interamericano Económico y Social (CIES).

(2002b): La calidad del empleo en el Perú, Red de políticas de empleo, Lima, Consejo Interamericano Económico y Social (CIES).

Iguiñiz, J. (2001): Desarrollo económico reciente del Perú, Pobreza y desarrollo en el Perú, Lima, Oxford Famine Relief Organization (OXFAM).

Ichniowski, C., K. Shaw y G. Prennushi (1995): The Effects of Human Resource Management Practices on Productivity, NBER Working Paper, Nº W5333, Cambridge, Massachusetts. 
INEI (Instituto Nacional de Estadística e Informática) (2004): Cuentas nacionales del Perú, www.inei.gob.pe, abril.

IPE (Instituto Peruano de Economía) (2001): Productividad y crecimiento económico en el Perú, Lima, mayo.

(2002a): Estado actual de la infraestructura de servicios públicos: estimación de la brecha de inversión, Lima.

(2002b): Impacto de la infraestructura de servicios públicos sobre la productividad de la economía peruana, Lima.

Katz, J. (2000): Reformas estructurales, productividad y conducta tecnológica, Santiago de Chile, Fondo de Cultura Económica (FCE)/Comisión Económica para América Latina y el Caribe (CEPAL).

Martínez, D. y V. Tokman (1997): Costo laboral y competitividad en el sector manufacturero de América Latina, Costos laborales y competitividad industrial en América Latina, Ginebra, Organización Internacional del Trabajo (OIT).

(1999): Costos laborales y productividad: estrategias para la competitividad, Inseguridad laboral y competitividad, Lima, Organización Internacional del Trabajo (OIT).

Moguillansky, G. (1996): El contexto macroeconómico y la inversión en América Latina, Revista de la CEPAL, N 58, LC/G.1916-P, Santiago de Chile, abril.
Porter, M. (1998): The Competitive Advantage of Nations, Nueva York, The Free Press

(2003): Building the Microeconomic Foundations of Prosperity: Findings from the Microeconomic Competitiveness Index, www.worldeconomicforum.org.

Rodrik, D. (2003): Growth Strategies, NBER Working Paper, No 10050 Cambridge, Massachusetts, National Bureau of Economic Research (NBER).

Sierra, J. y E. Sato (2002): Políticas para mejorar la calidad del empleo en las PYMES, Red de políticas de empleo, Lima, Consejo Interamericano Económico y Social (CIES).

Stiglitz, J. (1998 ): Más instrumentos y metas más amplias para el desarrollo: hacia el consenso post-Washington, Desarrollo económico, vol. 38, $\mathrm{N}^{\circ}$ 151, Buenos Aires, Instituto de Desarrollo Económico y Social, octubre-diciembre.

Svarzman, G. (2004): La política de exportaciones y la integración en el Mercosur, Estrategia de crecimiento y empleo en el Mercosur, Lima, Organización Internacional del Trabajo (OIT), abril, versión preliminar.

Williamson, J. (2003): Exchange rate policy and development, Initiative for Policy Dialogue (IPD), Columbia, University of Columbia. 